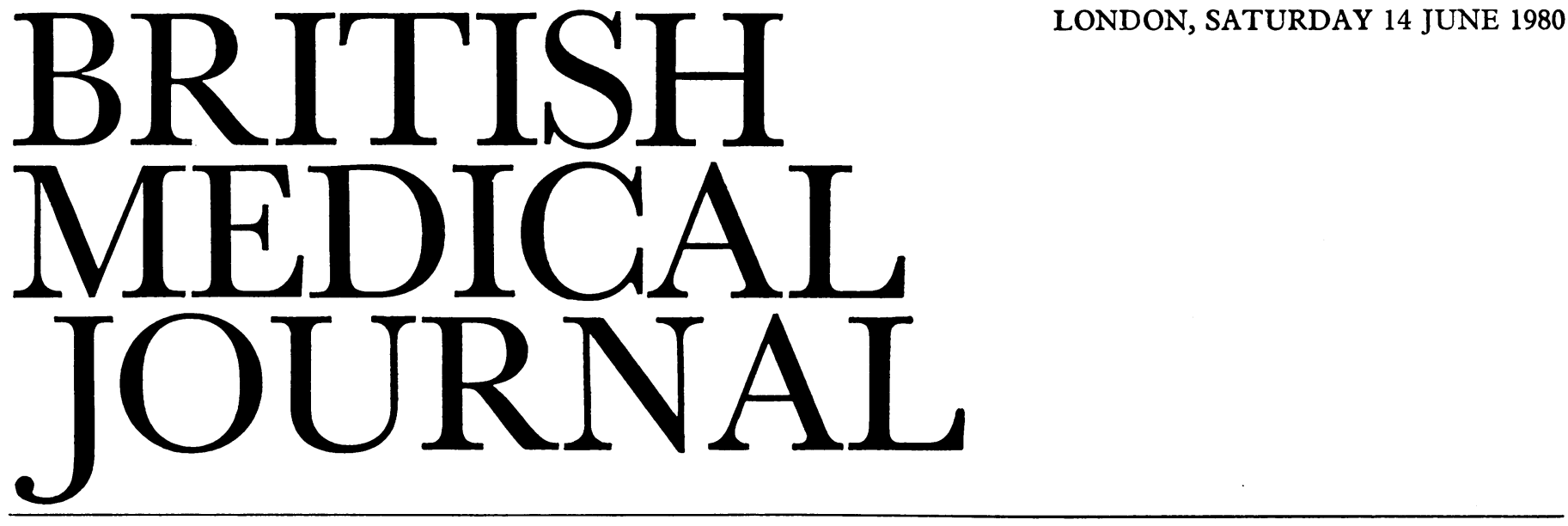

\title{
Research and risk
}

In times of financial stringency, when many valued activities have to be cut back, medical research is inevitably regarded as more expendable than clinical medicine and teaching. But how does that policy affect the long-term health of medicine? Should we not instead be looking for ways of strengthening research within the limits of the money available?

At the very least the options need to be debated, and three recent contributions have provided food for thought. Last week Dr Michael Stoker, in the second Francis Fraser lecture to the British Postgraduate Medical Federation, spoke about "new medicine and new biology." A working group of the Ciba Foundation that has been considering the problems and prospects of academic medicine, including research, has just held a meeting to discuss the issues. Finally, the first publication of the Association of Researchers in Medical Sciences, an organisation formed a few years ago to publicise the problems of research workers, has highlighted the disadvantages and the indignities of the short-term grant system and proposed radical reorganisation.

Medical research needs "risk capital" to nurture its growing points. Perutz relates how in 1947 Sir Lawrence Bragg told Sir Edward Mellanby, then secretary of the Medical Research Council, about a "treasure hunt with only the remotest chance of success" that could lead to understanding the workings of life on the molecular scale. ${ }^{1}$ So began what became the Laboratory of Molecular Biology. Today molecular biology impinges on clinical medicine, ${ }^{2}$ but even now its claims are often regarded sceptically; and Dr Stoker's lecture concluded that, of the chief clinical achievements of recent years, only transplantation, with its reliance on HLA typing, owed anything to the new biology. But, as he also observed, success with infectious diseases came long after Pasteur; and he predicted equally revolutionary results in the future from molecular and cell biology, including full understanding of cancer mechanisms and manipulation of the germ line to compensate for hereditary defects.

Despite a shorter time scale and more directly practical goals, even in clinical research only a small proportion of papers may turn out 20 years later to have been fruitful. ${ }^{3} \mathrm{~A}$ large study, based on over 500 "key" papers, showed that $41 \%$ of work considered crucial to later clinical advance was not clinically oriented at the time it was done, and that $62 \%$ of the papers dealt with basic research. ${ }^{4}$ To generate advance, then, a broad base of research, both clinical and non-clinical, must be supported and risks taken.
Research is also integral to academic medicine because it underpins teaching and has intellectual value for both teachers and students; and its present difficulties are thus a double cause of concern. Not only has funding deteriorated in recent years but research costs have risen. Moreover, student-staff ratios and clinical loads have increased, teaching and service commitments necessarily having priority over research. The system whereby the DHSS provided clinical resources for research has lapsed through lack of money; and the cost of translating findings into practice is no longer met from DHSS development funds. The chief casualty in all this is the unearmarked money that is so vital for exploiting new ideas and unpredicted opportunities.

One suggestion of the Ciba group demands particular attention: more time could be freed for research if the medical curriculum put less emphasis on formal instruction and more on self-education-an approach anyhow more appropriate to a university. The device of appointing a research worker to a lectureship rather than a research fellowship might also be encouraged further, so that more staff have time to do their own research and can continue to do it throughout their careers. Other suggestions for a more productive use of resources were the concentration of particular types of research in a few universities and the creation of much bigger academic departments.

More flexible funding could be restored, suggests the Ciba group, by reducing the money tied up in long-term research$60 \%$ of the MRC's budget is so deployed, while the University Grant Committee's funds can now provide little "seed money." This, however, would be anathema to many since the dearth of stable careers in research and the disadvantages of short-term grants already present problems. The Association of $\mathrm{Re}-$ searchers in Medical Sciences puts forward the opposite view. ${ }^{5}$ It points out that some $£ 80 \mathrm{~m}$ of the $£ 200 \mathrm{~m}$ or so spent annually on biomedical research by British government agencies and charities goes to research lasting two to three years; and, of the 4000-5000 research workers supported thus, $80 \%$ are aged $20-35$. They have no security of tenure and may be unemployed at $35 .{ }^{6}$ Broadly based and innovatory approaches are rare because of limited time, the research tending to be traditional with a clear-cut and relatively narrow endpoint. Furthermore, since tenure posts are scarce there is a shortage of experienced teachers for the research workers expecting to be trained. But how typical were the 140 members of the association who answered its "non-obligatory" questionnaire, 
and what proportion were medically qualified-or is it largely scientists without a medical degree who are affected? Despite the report's shortcomings, however, its proposals should be taken seriously. The $£ 80 \mathrm{~m}$ used for short-term contracts, the association calculates, could fund instead some 5000 permanent research staff and 2400 postgraduate students. It recommends better integration of funding agencies to co-ordinate policies and a career structure similar to that of hospital medicine, with a professional body to promote the interests and maintain the standards of research workers.

Neither this proposal nor the Ciba suggestion of more shortterm grants is likely to be widely accepted in the near future; but might not both be tried, on a limited scale in different centres, with detailed evaluations ? Meanwhile other aspects of careers and remuneration need attention. Financially as well as in terms of risk, a doctor choosing an academic career may be penalised in several ways; and the quantity and quality of applicants inevitably suffer. ${ }^{7}$ The Ciba meeting agreed that research fellowships should carry much higher stipends and that there should be parity of salaries and conditions of service between the universities and NHS, including distinction awards that take account of academic excellence and compensation for forgoing sessions of private practice and, in the case of younger doctors, extra duty allowances. The system that forces Nobel prizewinners to earn less than clinical research workers also needs scrutiny. But if money is to be found for all this clearly more economic types of organisation will have to be developed. Another change needed is in attitudes to research. A doctor who is fired to do a spell of research should be encouraged, and not penalised if he returns to the clinical ladder; training schedules should be devised less rigidly and with more sympathy for clinical science. ${ }^{8}$

Too few research workers of high calibre and too few leaders of research; thought the Ciba meeting, are emerging in Britain and this is not a problem only of money. Training students, at school and university, how to think and how to discover the excitement of medical science-in the face perhaps of popular disillusion with science-need not cost money; but it calls for a radical look at both examination syllabuses and teaching.

${ }_{1}^{1}$ Perutz MF. Origins of molecular biology. New Scientist 1980;85:326-9.

2 Perutz MF. Fundamental research in molecular biology: its relevance to medicine. In: Wolstenholme G, O'Connor M, eds. Research and medical practice: their interaction. Ciba Foundation Symposium 44 (new series). Amsterdam: Elsevier, Excerpta Medica, North-Holland, 1976:115-44.

3 Dickinson CJ. The value to medical practice of basic and applied medical research done twenty years ago. In: Wolstenholme G, O'Connor M, eds. Research and medical practice: their interaction. Ciba Foundation Symposium 44 (new series). Amsterdam: Elsevier, Excerpta Medica, North-Holland, 1976:53-72.

4 Comroe JH, Dripps RD. Scientific basis for the support of biomedical science. Science 1976;192:105-11.

${ }^{5}$ Association of Researchers in Medical Sciences. The case for careers in medical research. London: Association for Researchers in Medical Sciences, 1980 (obtainable from Clinical Science Laboratories, 17th Floor Guy's Tower, Guy's Hospital, London SE1 9RT).

${ }_{6}$ Anonymous. Not wanted at thirty-five. Lancet 1979; :912-3.

7 Anonymous. MDs or PhDs in medical research ? Br Med f 1980;280:274.

${ }^{8}$ Booth CC. The development of clinical science in Britain. Br Med f 1979; i: $1469-73$.

\section{Newly acquired right bundle-branch block}

The currently accepted electrocardiographic criteria of right bundle-branch block were defined in $1932^{1}$; yet despite the vast numbers of publications that have appeared since then the clinical implications of this electrocardiographic sign remain largely unknown. Established associations include hypertension, coronary heart disease, valvular heart disease, congenital heart disease, pulmonary embolism, pulmonary hypertension, and cardiomyopathy. ${ }^{2} 3$ But what is the significance of newly acquired right bundle-branch block? Is it an ominous warning of further serious cardiovascular disease and possible death, or is it an electrocardiographic abnormality of little prognostic importance in itself?

Few studies have answered these important questions satisfactorily. Most do not distinguish between recently acquired and old right bundle-branch block. Others have studied selected populations, and almost all lack adequate controls. A recent study from Framingham, however, has provided some specific answers. ${ }^{4}$ The incidence of newly acquired right bundle-branch block was low; only 70 cases were accumulated after 18 years' follow-up of 5193 people. Such a small number of patients means that we must be cautious about applying the results generally. Data were collected every two years at routine check-ups, patients who developed right bundle-branch block and subsequently died before their next routine visit thus being excluded. With these reservations, the study provides some valuable data for the general physician.

The incidence of right bundle-branch block increased with age, and in $70 \%$ of cases its onset was preceded by the diagnosis of some cardiovascular disorder. These disorders included hypertension, cardiac enlargement on chest radiographs, congestive heart failure, valvular heart disease, and diabetes. Hypertension was associated most frequently, occurring in $60 \%$ of cases. Each cardiovascular abnormality occurred twice as often in patients with right bundle-branch block as in controls. After the development of right bundlebranch block the incidence of coronary heart disease and congestive heart failure was two and a half and four times respectively that seen during the same period in the controlsa difference reflected in an increased accumulative death rate from cardiovascular disease at each two-year interval after the onset of right bundle-branch block. Analysis of the QRS duration provided impressive prognostic data. Of the 12 people with a QRS duration of $140 \mathrm{~ms}$, six died of cardiovascular disease and all developed clinical cardiovascular abnormalities. In contrast, in those with a QRS duration of $120 \mathrm{~ms}$ one-third remained free from all cardiovascular abnormalities during the follow-up period.

The development of right bundle-branch block may be an early sign of conducting tissue disease that will eventually progress to complete heart block with the development of Stokes-Adams attacks. ${ }^{5}$ In this study, however, only four individuals developed evidence of higher degrees of atrioventricular block. Eventual treatment with a pacemaker seems to be needed only rarely in such patients with right bundle-branch block. ${ }^{6}$

The conclusion to be drawn from this study is that right bundle-branch block most commonly occurs in people who have or will soon develop clinically apparent cardiovascular disease; when there is no clinically apparent disease the cause of right bundle-branch block is unclear. In a study of 37 pilots, for example, who underwent cardiac catheterisation because of newly acquired right bundle-branch block, almost all had a mildly raised end-diastolic pressure, possibly suggesting a diffuse abnormality of the ventricular myocardium. ${ }^{7}$

What should the physician do, therefore, when faced with 